\title{
Using Probiotics to Flatten the Curve of Coronavirus Disease COVID-2019 Pandemic
}

\author{
David Baud ${ }^{1}$, Varvara Dimopoulou Agri ${ }^{2}$, Glenn R. Gibson ${ }^{3}$, Gregor Reid ${ }^{4,5}$ and \\ Eric Giannoni ${ }^{2 *}$
}

1 Materno-Fetal and Obstetrics Research Unit, Department Woman-Mother-Child, Lausanne University Hospital, University of Lausanne, Lausanne, Switzerland, ${ }^{2}$ Clinic of Neonatology, Department Woman-Mother-Child, Lausanne University Hospital, University of Lausanne, Lausanne, Switzerland, ${ }^{3}$ Food and Nutritional Sciences, St Joseph's Hospital, The University of Reading, Reading, United Kingdom, ${ }^{4}$ Department of Microbiology and Immunology, The University of Western Ontario, London, ON, Canada, ${ }^{5}$ Canadian R\&D Centre for Human Microbiome and Probiotics, Lawson Health Research Institute, London, ON, Canada

Keywords: COVID 19, probiotics, prebiotics, SARS-CoV-2, pandemics, coronavirus, respiratory infection

\section{INTRODUCTION}

Despite strategies based on social distancing, hygiene, and screening, COVID-19 is progressing rapidly throughout the world, with healthcare systems at risk of being overwhelmed. While identification of effective drug therapies is ongoing, vaccines will not be available in the near future. Therefore, additional preventive strategies are urgently needed.

COVID-19 presents with a spectrum of disease severity, ranging from mild and non-specific flulike symptoms, to pneumonia, and life-threatening complications such as acute respiratory distress syndrome (ARDS) and multiple organ failure. While transmission of SARS-CoV-2 is thought to occur mainly via respiratory droplets, the gut may also contribute toward the pathogenesis of COVID-19 (1). SARS-CoV-2 RNA has been detected in the gastrointestinal tract and stool samples from patients (2-4), and in sewage systems (5). Coronaviruses, including SARS-Cov-2 can invade enterocytes, thereby acting as a reservoir for the virus (4). Indeed, large clinical studies from China indicate that gastrointestinal symptoms are common in COVID-19, and are associated with disease severity $(3,4)$.

Probiotics are live microorganisms that when administered in adequate amounts confer a health benefit on the host (6). Clinical evidence shows that certain probiotic strains help to prevent bacterial and viral infections, including gastroenteritis, sepsis, and respiratory tract infections (RTIs). The reason for adding probiotic strains to the overall prevention and care strategy is founded in science and clinical studies, albeit hitherto none directly on the etiological agent of this pandemic.

\section{CLINICAL DATA SUPPORTING THE USE OF PROBIOTICS TO PREVENT COVID-19}

Probiotics can prevent antibiotic-associated diarrhea, and infections in the gastrointestinal tract, but also infections at other sites, including sepsis, and RTIs (7-13). Meta-analyses are the gold standard for evidence-based medicine. In one analysis of more than 8,000 preterm infants included in randomized control trials (RCTs), patients receiving enteral supplementation with probiotics showed a reduction in necrotizing enterocolitis, nosocomial sepsis, and all-cause mortality (14). A well-conducted RCT including $>4,000$ newborns in India found a reduction in sepsis and lower RTIs in infants treated with a strain of Lactobacillus plantarum combined with prebiotics (which are growth substrates specific for beneficial microorganisms) (15).

Viruses are etiologic agents of over $90 \%$ of upper RTIs. The positive impact of probiotics on prevention of upper RTIs is documented in a number of studies. A meta-analysis of 12 RCTs 
including 3,720 adults and children reported a 2-fold lower risk of developing upper RTI in subjects taking probiotics, and a small but significant reduction in disease severity in those infected. A randomized, double-blind, placebo-controlled intervention study of 479 adults showed that Lactobacillus gasseri PA 16/8, Bifidobacterium longum SP 07/3, and Bifidobacterium bifidum MF 20/5 with vitamins and minerals lowered not only the duration of common cold episodes but also days with fever (16). The impact of probiotics on prevention of upper RTIs caused by specific viruses has also been documented. An RCT including 94 preterm infants showed that galactooligosaccharide and polydextrose prebiotic mixture (1:1), or probiotic Lactobacillus rhamnosus GG given between 3 and 60 days of life lowered the incidence of clinically defined virusassociated RTI by 2- to 3-fold compared to placebo (17). The incidence of rhinovirus-associated episodes, which comprised $80 \%$ of all RTIs in this study, was also strongly reduced with probiotics or prebiotics. The incidence of influenza RTI was reduced following consumption of Lactobacillus brevis in an open label study of 1,783 school children (18). Pertinent to the pandemic affecting adults more than children, these positive findings were confirmed in an RCT that included 27 elderly subjects receiving Bifidobacterium longum or placebo (19). Furthermore, lactic acid bacteria, from which many probiotics are selected, are part of the upper respiratory tract microbiota in healthy people, and some strains are being considered for prevention of recurrent otitis media $(20,21)$. This makes their use for contributing to slow down progression of the coronavirus pandemic worthy of consideration.

Probiotics have also been used to prevent bacterial lower RTIs in critically ill adults. Meta-analyses of RCTs including close to 2,000 patients found that probiotic strains reduce the incidence of ventilator-associated pneumonia $(22,23)$. But low quality of evidence and conflicting results among different studies calls for additional well-conducted RCTs.

It should be noted that not all probiotics, even those with gastrointestinal benefits, necessarily contribute in every way to reducing the risk of respiratory infection. For example, Lactobacillus rhamnosus GG and Bifidobacterium animalis ssp. lactis may contribute to intestinal benefits, but do not reduce the number of viruses in the nasopharynx (24). Examples of products that could be considered, depending on availability in a given country, are provided in Table 1.

\section{MECHANISTIC BASIS FOR THE ACTION OF PROBIOTICS TO PREVENT INFECTIONS AND RELEVANCE TO COVID-19}

Mechanisms that might explain clinical success of probiotics include enhancement of the intestinal epithelial barrier, competition with pathogens for nutrients and adhesion to the intestinal epithelium, production of anti-microbial substances and modulation of the host immune system (28). An RCT of 55 infants showed that enteral supplementation with a combination of Bifidobacterium bifidum and Streptococcus thermophilus reduced the incidence of diarrhea and shedding of rotaviruses (29), an effect that has been confirmed in subsequent studies (30). This would indicate interference with viral entry into cells and/or inhibition of viral replication in the intestine. While this mechanism may have a role in reducing dissemination of coronavirus via the gut, the probiotic strains were not administered to the respiratory tract. So, direct inhibition may

TABLE 1 | The following are examples (not exclusive) of probiotic products, or web sites listing products, with documentation in human studies that may have relevance to reducing the burden of the coronavirus pandemic.

\begin{tabular}{|c|c|c|c|}
\hline Products & Basis for inclusion & When to administer & References \\
\hline $\begin{array}{l}\text { Lactobacillus casei DN-114 001; DanActive/Actimel } \\
\text { Fermented drink, Danone }\end{array}$ & Reduced incidence and duration of RTIs & Once daily for duration of the pandemic & $(12,13)$ \\
\hline $\begin{array}{l}\text { Lactobacillus gasseri PA 16/8, Bifidobacterium } \\
\text { longum SP 07/3, and B. bifidum MF 20/5; Tribion } \\
\text { harmonis, Merck }\end{array}$ & $\begin{array}{l}\text { Lowering duration and severity of flu-like } \\
\text { illness }\end{array}$ & Once daily for duration of the pandemic & $(16)$ \\
\hline $\begin{array}{l}\text { Lactobacillus rhamnosus GG; Culturelle or other } \\
\text { brand names }\end{array}$ & $\begin{array}{l}\text { For digestive health and gut barrier } \\
\text { integrity, and prevention of viral RTIs }\end{array}$ & $\begin{array}{l}\text { One capsule daily for duration of the } \\
\text { pandemic }\end{array}$ & $(17)$ \\
\hline Lactobacillus plantarum DR7; Malaysia & $\begin{array}{l}\text { Prevention of upper RTIs, immune } \\
\text { modulation }\end{array}$ & $\begin{array}{l}2 \mathrm{~g} \text { sachet per day for duration of } \\
\text { pandemic }\end{array}$ & (25) \\
\hline $\begin{array}{l}\text { Bifidobacterium breve Yakult, and Lactobacillus } \\
\text { casei Shirota; available as fermented drinks }\end{array}$ & $\begin{array}{l}\text { Lower incidence of ventilator-associated } \\
\text { pneumonia }\end{array}$ & $\begin{array}{l}\text { One of each day for duration of the } \\
\text { pandemic }\end{array}$ & (26) \\
\hline $\begin{array}{l}\text { Bifidobacterium longum BB536; Morinaga, and sold } \\
\text { in many formulations }\end{array}$ & $\begin{array}{l}\text { Enhances innate immunity, prevents } \\
\text { influenza infection }\end{array}$ & One each day for duration of the pandemic & (19) \\
\hline $\begin{array}{l}\text { Pediococcus pentosaceus 5-33:3, Leuconostoc } \\
\text { mesenteroides 32-77:1, L. paracasei ssp. paracasei } \\
\text { 19, L. plantarum 2,362 plus inulin, oat bran, pectin, } \\
\text { and resistant starch; Medipharm, Sweden }\end{array}$ & $\begin{array}{l}\text { To reduce rate of SIRS, infections, sepsis, } \\
\text { days of stay in the intensive care unit, days } \\
\text { under mechanical ventilation, and mortality }\end{array}$ & For COVID-19 patients & $(27)$ \\
\hline \multicolumn{4}{|c|}{ A list of probiotics available in Canada for various health issues; www.probioticchart.ca } \\
\hline \multicolumn{4}{|c|}{ A list of probiotics available in the USA for various health issues; www.usprobioticguide.com } \\
\hline
\end{tabular}

We must emphasize that none have been tested or proven to have an effect against SARS-CoV2, the virus causing COVID-19, nor are they proven treatments or cures for this condition. 
appear impossible at this site. Having said that, lungs have their own microbiota and a gut-lung connection has been described whereby host-microbe, microbe-microbe and immune interactions can influence the course of respiratory diseases (31). RTIs such as influenza are associated with an imbalance in the microbial communities of the respiratory and gastrointestinal tracts $(32,33)$. This dysbiosis may alter subsequent immune function and predispose to secondary bacterial infection. As reports from China indicate that COVID-19 might be associated with intestinal dysbiosis causing inflammation and poorer response to pathogens $(34,35)$, the case exists for probiotic strains that restore gut homeostasis (36). It is feasible that orally administered probiotic strains could further influence this gut-lung axis, as some can migrate from the gut to distant sites, such as the breast to treat mastitis (37).

The gut microbiome has a critical impact on systemic immune responses, and immune responses at distant mucosal sites, including the lungs $(38,39)$. Administration of certain bifidobacteria or lactobacilli has beneficial impact on influenza virus clearance from the respiratory tract $(39,40)$. Probiotic strains improve levels of type I interferons, increase the number and activity of antigen presenting cells, NK cells, T cells, as well as the levels of systemic and mucosal specific antibodies in the lungs $(16,19,39)$. There is also evidence that probiotic strains modify the dynamic balance between proinflammatory and immunoregulatory cytokines that allow viral clearance while minimizing immune response-mediated damage to the lungs. This might be particularly relevant to prevent ARDS, a major complication of COVID-19. An RCT with Lactobacillus plantarum DR7 showed suppression of plasma pro-inflammatory cytokines (IFN- $\gamma, \mathrm{TNF}-\alpha$ ) in middle-aged adults, and enhancement of anti-inflammatory cytokines (IL-4, IL-10) in young adults, along with reduced plasma peroxidation and oxidative stress levels (25). Given the cytokine storm that appears to occur in many COVID-19 patients, this type of modulation may prove to be very important. The manner in which orally administered probiotic strains contributes to this appears to involve the immune response emanating from the intestine, a focal point of the body's defenses. Therefore, probiotic strains documented to enhance the integrity of tight junctions, for example through increasing butyrate, a fuel for colonocytes could theoretically reduce SARS-Cov-2 invasion.

Evidence for antiviral activity of probiotic strains against common respiratory viruses, including influenza, rhinovirus, and respiratory syncytial virus comes from clinical and experimental studies $(17-19,41)$. While none of these effects or mechanisms have been tested on the new SARS-CoV-2 virus, this should not negate considering this approach, especially when effects of probiotics against other coronavirus strains have been reported (42-45). Furthermore, patients are dying from secondary bacterial infections. A recent study in mice has shown that oral

\section{REFERENCES}

1. Ng SC, Tilg H. COVID-19 and the gastrointestinal tract: more than meets the eye. Gut. (2020). doi: 10.1136/gutjnl-2020-3 21195. [Epub ahead of print]. administration of Lactobacillus acidophilus CMCC878, started $24 \mathrm{~h}$ after pulmonary inoculation of Pseudomonas aeruginosa and Staphylococcus aureus reduced bacterial load in the lungs, and decreased lung damage and systemic inflammation (46).

\section{SAFETY OF PROBIOTICS}

Probiotics are generally safe, even in the most vulnerable populations and in intensive care settings $(14,47)$. Cases of probiotic-associated bacteremia and fungaemia have occurred on extremely rare occasions, mainly in premature and immunocompromised patients treated with preparations lacking adequate quality control $(48,49)$. Rather than consider intensive care patients too ill to receive probiotic and prebiotic therapy, RCTs of probiotics for the prevention of ventilatorassociated pneumonia provide a reason to consider them $(22,23,26)$. Moreover, in an RCT of 65 critically ill, mechanically ventilated, multiple trauma patients, the synbiotic Pediococcus pentosaceus 5-33:3, Leuconostoc mesenteroides 32-77:1, L. paracasei ssp. paracasei 19, L. plantarum 2,362 plus inulin, oat bran, pectin, and resistant starch resulted in reduced rate of infections, systemic inflammatory response syndrome, sepsis, days of stay in the intensive care unit, days under mechanical ventilation, and mortality (27).

\section{SUMMARY}

In summary, orally administered probiotic strains can reduce the incidence and severity of viral RTIs. At a time when doctors are using drugs with little anti- COVID-19 data, probiotic strains documented for anti-viral and respiratory activities (not low-quality undocumented imitations) should become part of the armamentarium to reduce the burden and severity of this pandemic. Government funding is being used to test numerous drugs but just as important, they should fund probiotic trials. In addition, use of recognized prebiotics (e.g., fructans, galactans) to enhance propagation of probiotic strains and indigenous beneficial microbes should be recommended as part of the overall strategy to flatten the curve $(11,50)$.

\section{AUTHOR CONTRIBUTIONS}

EG, DB, and VD contributed conception of the manuscript. EG and VD wrote the first draft. DB, GG, and GR wrote sections of the manuscript. All authors contributed to manuscript revision, read, and approved the submitted version.

\section{FUNDING}

EG is supported by the Leenaards Foundation.

2. Pan Y, Zhang D, Yang P, Poon LLM, Wang Q. Viral load of SARSCoV-2 in clinical samples. Lancet Infect Dis. (2020) 20:411-2. doi: 10.1016/S1473-3099(20)30113-4

3. Jin X, Lian JS, Hu JH, Gao J, Zheng L, Zhang YM, et al. Epidemiological, clinical and virological characteristics of 74 cases of coronavirus-infected 
disease 2019 (COVID-19) with gastrointestinal symptoms. Gut. (2020). doi: 10.1136/gutjnl-2020-320926. [Epub ahead of print].

4. Lin L, Jiang X, Zhang Z, Huang S, Zhang Z, Fang Z, et al. Gastrointestinal symptoms of 95 cases with SARS-CoV-2 infection. Gut. (2020). doi: 10.1136/gutjnl-2020-321013. [Epub ahead of print].

5. Wu F, Xiao A, Zhang J, Gu X, Lee WL, Kauffman K, et al. SARS-CoV-2 titers in wastewater are higher than expected from clinically confirmed cases. medRxiv. (2020). doi: 10.1101/2020.04.05.20051540. [Epub ahead of print].

6. Hill C, Guarner F, Reid G, Gibson GR, Merenstein DJ, Pot B, et al. Expert consensus document. The International Scientific Association for Probiotics and Prebiotics consensus statement on the scope and appropriate use of the term probiotic. Nat Rev Gastroenterol Hepatol. (2014) 11:506-14. doi: 10.1038/nrgastro.2014.66

7. Szajewska H, Kolodziej M, Gieruszczak-Bialek D, Skorka A, Ruszczynski M, Shamir R. Systematic review with meta-analysis: Lactobacillus rhamnosus GG for treating acute gastroenteritis in children-a 2019 update. Aliment Pharmacol Ther. (2019) 49:1376-84. doi: 10.1111/apt.15267

8. Goldenberg JZ, Yap C, Lytvyn L, Lo CK, Beardsley J, Mertz D, et al. Probiotics for the prevention of Clostridium difficile-associated diarrhea in adults and children. Cochrane Database Syst Rev. (2017) 12:CD006095. doi: 10.1002/14651858.CD006095.pub4

9. Guo Q, Goldenberg JZ, Humphrey C, El Dib R, Johnston BC. Probiotics for the prevention of pediatric antibiotic-associated diarrhea. Cochrane Database Syst Rev. (2019) 4:CD004827. doi: 10.1002/14651858.CD004827.pub5

10. Lenoir-Wijnkoop I, Gerlier L, Roy D, Reid G. The clinical and economic impact of probiotics consumption on respiratory tract infections: projections for Canada. PLoS ONE. (2016) 11:e0166232. doi: 10.1371/journal.pone.0166232

11. Pregliasco F, Anselmi G, Fonte L, Giussani F, Schieppati S, Soletti L. A new chance of preventing winter diseases by the administration of synbiotic formulations. J Clin Gastroenterol. (2008) 42(Suppl.3):S224-33. doi: 10.1097/MCG.0b013e31817e1c91

12. Guillemard E, Tondu F, Lacoin F, Schrezenmeir J. Consumption of a fermented dairy product containing the probiotic Lactobacillus casei DN-114001 reduces the duration of respiratory infections in the elderly in a randomised controlled trial. Br J Nutr. (2010) 103:58-68. doi: 10.1017/S0007114509991395

13. Guillemard E, Tanguy J, Flavigny A, de la Motte S, Schrezenmeir J. Effects of consumption of a fermented dairy product containing the probiotic Lactobacillus casei DN-114 001 on common respiratory and gastrointestinal infections in shift workers in a randomized controlled trial. J Am Coll Nutr. (2010) 29:455-68. doi: 10.1080/07315724.2010.10719882

14. Dermyshi E, Wang Y, Yan C, Hong W, Qiu G, Gong X, et al. The "golden age" of probiotics: a systematic review and meta-analysis of randomized and observational studies in preterm infants. Neonatology. (2017) 112:9-23. doi: $10.1159 / 000454668$

15. Panigrahi P, Parida S, Nanda NC, Satpathy R, Pradhan L, Chandel DS, et al. A randomized synbiotic trial to prevent sepsis among infants in rural India. Nature. (2017) 548:407-12. doi: 10.1038/nature23480

16. de Vrese M, Winkler P, Rautenberg P, Harder T, Noah C, Laue C, et al. Effect of Lactobacillus gasseri PA 16/8, Bifidobacterium longum SP 07/3, B. bifidum MF 20/5 on common cold episodes: a double blind, randomized, controlled trial. Clin Nutr. (2005) 24:481-91. doi: 10.1016/j.clnu.2005.02.006

17. Luoto R, Ruuskanen O, Waris M, Kalliomaki M, Salminen S, Isolauri E. Prebiotic and probiotic supplementation prevents rhinovirus infections in preterm infants: a randomized, placebo-controlled trial. J Allergy Clin Immunol. (2014) 133:405-13. doi: 10.1016/j.jaci.2013.08.020

18. Waki N, Matsumoto M, Fukui Y, Suganuma H. Effects of probiotic Lactobacillus brevis KB290 on incidence of influenza infection among schoolchildren: an open-label pilot study. Lett Appl Microbiol. (2014) 59:56571. doi: 10.1111/lam.12340

19. Namba K, Hatano M, Yaeshima T, Takase M, Suzuki K. Effects of Bifidobacterium longum BB536 administration on influenza infection, influenza vaccine antibody titer, and cell-mediated immunity in the elderly. Biosci Biotechnol Biochem. (2010) 74:939-45. doi: 10.1271/bbb.90749

20. Rautava S, Salminen S, Isolauri E. Specific probiotics in reducing the risk of acute infections in infancy-a randomised, double-blind, placebo-controlled study. Br J Nutr. (2009) 101:1722-6. doi: 10.1017/S0007114508116282
21. Cardenas N, Martin V, Arroyo R, López M, Carrera M, Badiola C, et al. Prevention of recurrent acute otitis media in children through the use of Lactobacillus salivarius PS7, a target-specific probiotic strain. Nutrients. (2019) 11:e376. doi: 10.3390/nu11020376

22. Bo L, Li J, Tao T, Bai Y, Ye X, Hotchkiss RS, et al. Probiotics for preventing ventilator-associated pneumonia. Cochrane Database Syst Rev. (2014) 10:CD009066. doi: 10.1002/14651858.CD009066.pub2

23. Su M, Jia Y, Li Y, Zhou D, Jia J. Probiotics for the prevention of ventilatorassociated pneumonia: a meta-analysis of randomized controlled trials. Respir Care. (2020) 65:5. doi: 10.4187/respcare.07097. [Epub ahead of print].

24. Lehtoranta L, Kalima K, He L, Lappalainen M, Roivainen M, Närkiö M, et al. Specific probiotics and virological findings in symptomatic conscripts attending military service in Finland. J Clin Virol. (2014) 60:276-81. doi: 10.1016/j.jcv.2014.03.021

25. Chong HX, Yusoff NAA, Hor YY, Lew LC, Jaafar MH, Choi SB, et al. Lactobacillus plantarum DR7 improved upper respiratory tract infections via enhancing immune and inflammatory parameters: a randomized, double-blind, placebo-controlled study. J Dairy Sci. (2019) 102:4783-97. doi: 10.3168/jds.2018-16103

26. Shimizu K, Yamada T, Ogura H, Mohri T, Kiguchi T, Fujimi S, et al. Synbiotics modulate gut microbiota and reduce enteritis and ventilatorassociated pneumonia in patients with sepsis: a randomized controlled trial. Crit Care. (2018) 22:239. doi: 10.1186/s13054-018-2167-x

27. Kotzampassi K, Giamarellos-Bourboulis EJ, Voudouris A, Kazamias P, Eleftheriadis E. Benefits of a synbiotic formula (Synbiotic 2000Forte) in critically Ill trauma patients: early results of a randomized controlled trial. World J Surg. (2006) 30:1848-55. doi: 10.1007/s00268-005-0653-1

28. Bermudez-Brito M, Plaza-Diaz J, Munoz-Quezada S, Gomez-Llorente C, Gil A. Probiotic mechanisms of action. Ann Nutr Metab. (2012) 61:160-74. doi: $10.1159 / 000342079$

29. Saavedra JM, Bauman NA, Oung I, Perman JA, Yolken RH. Feeding of Bifidobacterium bifidum and Streptococcus thermophilus to infants in hospital for prevention of diarrhoea and shedding of rotavirus. Lancet. (1994) 344:1046-9. doi: 10.1016/S0140-6736(94)91708-6

30. Gonzalez-Ochoa G, Flores-Mendoza LK, Icedo-Garcia R, Gomez-Flores R, Tamez-Guerra P. Modulation of rotavirus severe gastroenteritis by the combination of probiotics and prebiotics. Arch Microbiol. (2017) 199:953-61. doi: $10.1007 / \mathrm{s} 00203-017-1400-3$

31. Enaud R, Prevel R, Ciarlo E, Beaufils F, Wieërs G, Guery B, et al. The gut-lung axis in health and respiratory diseases: a place for inter-organ and inter-kingdom crosstalks. Front Cell Infect Microbiol. (2020) 10:9. doi: $10.3389 /$ fcimb.2020.00009

32. Sencio V, Barthelemy A, Tavares LP, Machado MG, Soulard D, Cuinat C, et al. Gut dysbiosis during influenza contributes to pulmonary pneumococcal superinfection through altered short-chain fatty acid production. Cell Rep. (2020) 30:2934-47 e6. doi: 10.1016/j.celrep.2020. 02.013

33. Hanada S, Pirzadeh M, Carver KY, Deng JC. Respiratory viral infection-induced microbiome alterations and secondary bacterial pneumonia. Front Immunol. (2018) 9:2640. doi: 10.3389/fimmu.2018. 02640

34. Gao QY, Chen YX, Fang JY. 2019 Novel coronavirus infection and gastrointestinal tract. J Dig Dis. (2020) 12:3. doi: 10.1111/1751-2980.12851. [Epub ahead of print].

35. Xu K, Cai H, Shen Y, Ni Q, Chen Y, Hu S, et al. Management of corona virus disease-19 (COVID-19): the Zhejiang experience. Zhejiang Da Xue Xue Bao Yi Xue Ban. (2020) 49.

36. Di Pierro F. A possible probiotic (S. salivarius K12) approach to improve oral and lung microbiotas and raise defenses against SARS-CoV-2. Minerva Med. (2020). doi: 10.23736/S0026-4806.20.06570-2. [Epub ahead of print].

37. Arroyo R, Martin V, Maldonado A, Jimenez E, Fernandez L, Rodriguez JM. Treatment of infectious mastitis during lactation: antibiotics versus oral administration of lactobacilli isolated from breast milk. Clin Infect Dis. (2010) 50:1551-8. doi: 10.1086/652763

38. Abt MC, Osborne LC, Monticelli LA, Doering TA, Alenghat T, Sonnenberg GF, et al. Commensal bacteria calibrate the activation threshold of innate antiviral immunity. Immunity. (2012) 37:158-70. doi: 10.1016/j.immuni.2012.04.011 
39. Zelaya H, Alvarez S, Kitazawa H, Villena J. Respiratory antiviral immunity and immunobiotics: beneficial effects on inflammation-coagulation interaction during influenza virus infection. Front Immunol. (2016) 7:633. doi: 10.3389/fimmu.2016.00633

40. Ichinohe T, Pang IK, Kumamoto Y, Peaper DR, Ho JH, Murray TS, et al. Microbiota regulates immune defense against respiratory tract influenza A virus infection. Proc Natl Acad Sci USA. (2011) 108:5354-9. doi: 10.1073/pnas.1019378108

41. Turner RB, Woodfolk JA, Borish L, Steinke JW, Patrie JT, Muehling LM, et al. Effect of probiotic on innate inflammatory response and viral shedding in experimental rhinovirus infection-a randomised controlled trial. Benef Microbes. (2017) 8:207-15. doi: 10.3920/BM2016.0160

42. Kumar R, Seo BJ, Mun MR, Kim CJ, Lee I, Kim H, et al. Putative probiotic Lactobacillus spp. from porcine gastrointestinal tract inhibit transmissible gastroenteritis coronavirus and enteric bacterial pathogens. Trop Anim Health Prod. (2010) 42:1855-60. doi: 10.1007/s11250-010-9648-5

43. Chai W, Burwinkel M, Wang Z, Palissa C, Esch B, Twardziok S, et al. Antiviral effects of a probiotic Enterococcus faecium strain against transmissible gastroenteritis coronavirus. Arch Virol. (2013) 158:799-807. doi: 10.1007/s00705-012-1543-0

44. Liu YS, Liu Q, Jiang YL, Yang WT, Huang HB, Shi CW, et al. Surface-displayed porcine IFN-lambda3 in Lactobacillus plantarum inhibits porcine enteric coronavirus infection of porcine intestinal epithelial cells. J Microbiol Biotechnol. (2019) 30:515-525. doi: 10.4014/jmb.1909.0 9041. [Epub ahead of print].

45. Wang K, Ran L, Yan T, Niu Z, Kan Z, Zhang Y, et al. Anti-TGEV miller strain infection effect of Lactobacillus plantarum supernatant based on the JAK-STAT1 signaling pathway. Front Microbiol. (2019) 10:2540. doi: 10.3389/fmicb.2019.02540

46. Shoaib A, Xin L, Xin Y. Oral administration of Lactobacillus acidophilus alleviates exacerbations in Pseudomonas aeruginosa and Staphylococcus aureus pulmonary infections. Pak J Pharm Sci. (2019) 32:1621-30.
47. Sanders ME, Merenstein DJ, Ouwehand AC, Reid G, Salminen S, Cabana MD, et al. Probiotic use in at-risk populations. J Am Pharm Assoc. (2016) 56:680-6. doi: 10.1016/j.japh.2016.07.001

48. Bertelli C, Pillonel T, Torregrossa A, Simonsen GS, Støen R, Klingenberg C. Bifidobacterium longum bacteremia in preterm infants receiving probiotics. Clin Infect Dis. (2015) 60:924-7. doi: 10.1093/cid/c iu946

49. Kolacek S, Hojsak I, Berni Canani R, Guarino A, Indrio F, Orel R, et al. Commercial probiotic products: a call for improved quality control. A position paper by the ESPGHAN Working Group for Probiotics and Prebiotics. $J$ Pediatric Gastroenterol Nutr. (2017) 65:117-24. doi: 10.1097/MPG.00000000000 01603

50. Chan CKY, Tao J, Chan OS, Li HB, Pang H. Preventing respiratory tract infections by synbiotic interventions: a systematic review and meta-analysis of randomized controlled trials. Adv Nutr. (2020). doi: 10.1093/advances/nmaa003. [Epub ahead of print].

Conflict of Interest: GG and GR provide advice to probiotic and prebiotic companies.

The remaining authors declare that the research was conducted in the absence of any commercial or financial relationships that could be construed as a potential conflict of interest.

Copyright (c) 2020 Baud, Dimopoulou Agri, Gibson, Reid and Giannoni. This is an open-access article distributed under the terms of the Creative Commons Attribution License (CC BY). The use, distribution or reproduction in other forums is permitted, provided the original author(s) and the copyright owner(s) are credited and that the original publication in this journal is cited, in accordance with accepted academic practice. No use, distribution or reproduction is permitted which does not comply with these terms. 